\title{
The model of energy efficiency transportation of thermal and electric energy in the underground heat collector
}

\author{
Dmitriy Titkov ${ }^{1, *}$ \\ ${ }^{1}$ National Research University Moscow State University of Civil Engineering, 129337, Yaroslavskaya \\ road, 26, Moscow, Russia
}

\begin{abstract}
The paper deals with modeling of the underground heat collector thermal conditions for utilities, calculating variations in temperature taking place in the soil mass around the collector as well as temperature variations in the air space of the latter. This leads to the reduction in the cost of heat and electricity transportation and a significant cost cutting of heat that is electricity supply of urban areas. The dependences of the thermal soil massiveness on the laying depth of the collector and changes in soil temperature in the course of time are presented.
\end{abstract}

\section{The problem of heat and electricity transportation cost reduction by controlling thermal conditions of the underground heat collector}

The problem of the underground heat collector energy efficiency providing is conditioned by the complexity of the engineering structure besides specific features of the surrounding soil and its thickness. This leads to many factors influencing conditions for the formation of the underground heat collector microclimate. These include the properties of the soil: thermal conductivity, thermal massiveness, heat absorption coefficient; outdoor air parameters and their change when passing through all layers (soil, enclosing structures of the collector) $[1,3,4,7]$. At the same time, thermal conditions control in the air space of the collector based on the EE principles results in cost cutting of heat or energy supply to urban areas and cost reduction of the heat consumption by consumers.

The use of mathematical modeling methods in the study and prediction of the out-door air temperature effect on the thermal conditions of the underground heat collector allows taking into account thermal massiveness of the soil and enclosing structures, amplitude decay of variations in temperature and changes in the time of heat exchange processes taking place in the thickness of the soil, enclosing structures and space of the collector $[2,5$, $6,8,9]$. The model must take into account the heat resistance of the enclosure and the fact that the heat exchange process between the collector and the outdoor air is not steady-state.

\footnotetext{
${ }^{*}$ Corresponding author: titkov1000@gmail.com
} 


\section{Background information for energy efficiency modeling}

To build a mathematical model in the process of research, it is necessary to identify the effect of outdoor air temperature on the temperature conditions change in the soil mass and to describe the unsteady-state processes of temperature influence time lag in the course of time.

Let us consider the temperature change in the soil mass, thermal massiveness and time shift depending on the outdoor air temperature at a depth of up to $1.2 \mathrm{~m}$ in increments of $0.1 \mathrm{~m}$ (see Fig. 1).

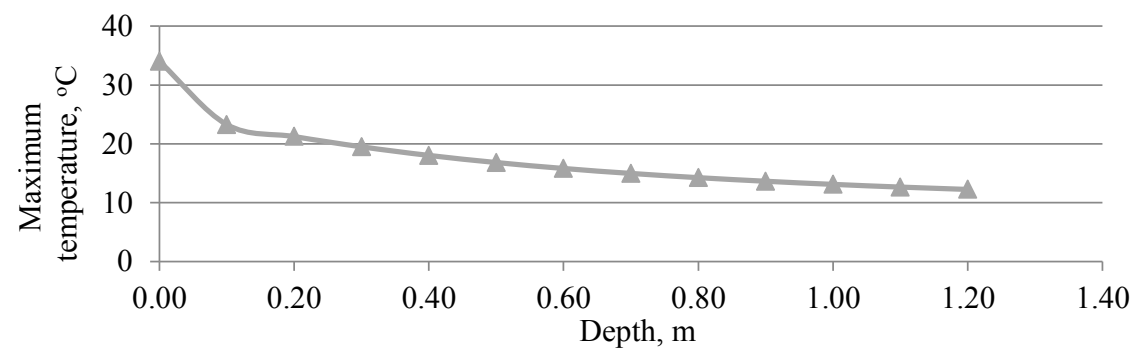

Fig. 1. Graph of the influence of the maximum outdoor temperature in the warm season on the soil at a depth of $1.2 \mathrm{~m}$.

At a depth of 1.1-1.2 m, the temperature in the soil column stabilizes and approaches the steady-state process of temperature change.

Due to the large thermal massiveness and considerable thickness of the soil mass, the processes of heat and mass transfer are not steady-state. The time variation of the soil heat transfer processes with the outdoor air occurs with a shift in time (phase shift) [10].

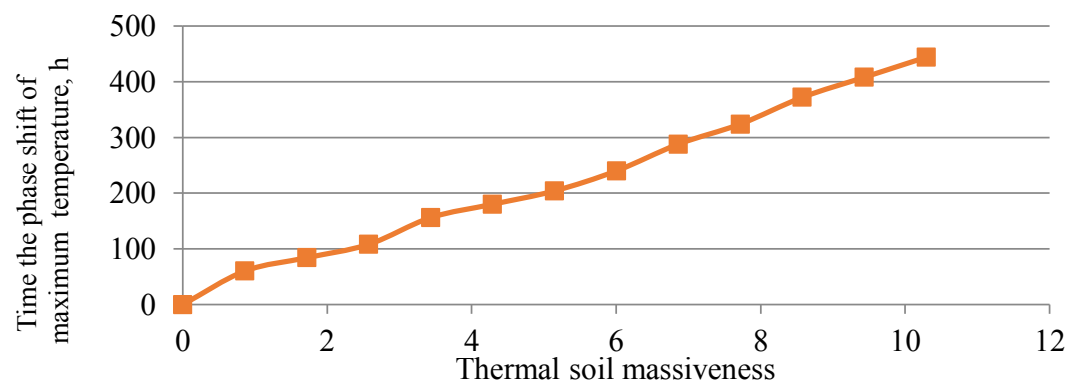

Fig. 2. Graph of time shift change (phase) according to the thermal massiveness of the soil.

The graph (see Fig. 2) also shows an increase in the time shift conditioned by the depth of the soil mass. It occurs with increasing depth, when the thermal massiveness increases as well and hence the time lag of the temperature conditions changes takes place [11].

Figure 3 is a graph presents the way of the time shift occurring according to the depth of the soil mass. 


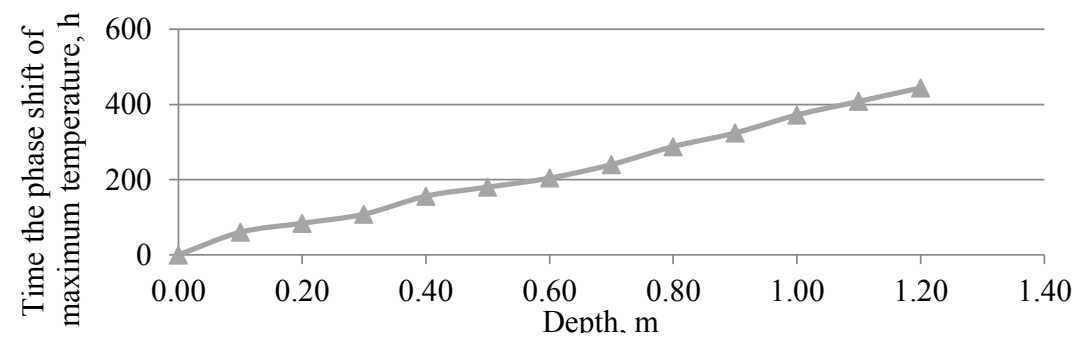

Fig. 3. Time shift graph depending on the depth of the soil mass.

With the change in depth, thermal inertia and thermal massiveness change as well and hence there is some shift in time of temperature change in the thickness of the soil [12].

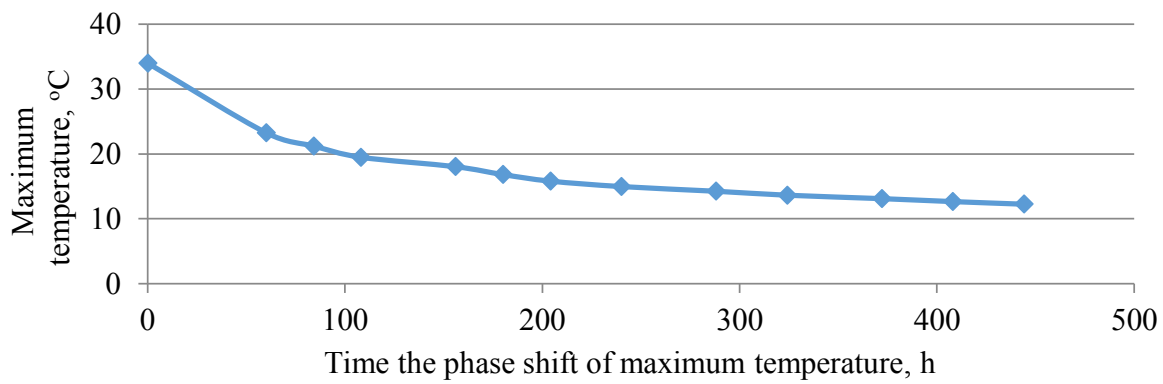

Fig. 4. Graph of the outdoor air temperature time shift alongside with the change of the temperature in the thickness of the soil column.

As can be seen from the graph in figure 4, the temperature change occurs with a time shift and the longer the phase shift the lower the temperature is, but within a certain period of time the temperature dependence on the time shift is equalized and approaches a relatively steady-state process [13]. Figure 5 and figure 6 have the graphs showing the influence of the outside air temperature alongside with the temperature in the soil column taking into account a time shift, being late in response of the temperature change depending on the depth with a step of $0.1 \mathrm{~m}$ [13].

Judging by the graphs in figure 5 and figure 6 it can be seen that the time shift and lag of temperature influence take place with each step of deepening into the soil. The graph in figure 5 shows the variations of the outdoor air temperature and allows seeing the air temperature change in the soil column comparing it with the change in the outdoor air temperature. Figure 6 presents the graphs of examining of the temperature conditions changes in the soil column without taking into account the graphs of the outdoor air temperature [14]. 


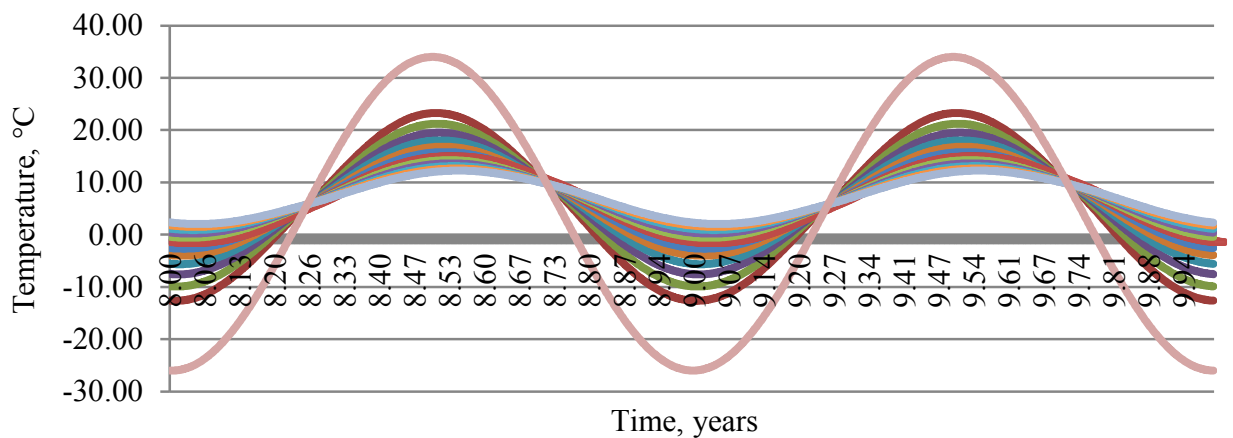

Fig. 5. Graph of influence of the outdoor air temperature alongside with the temperature in the soil column taking into account a time shift, being late in response of the temperature change depending on the depth with a step of $0.1 \mathrm{~m}$. reflecting outdoor air temperature changes.

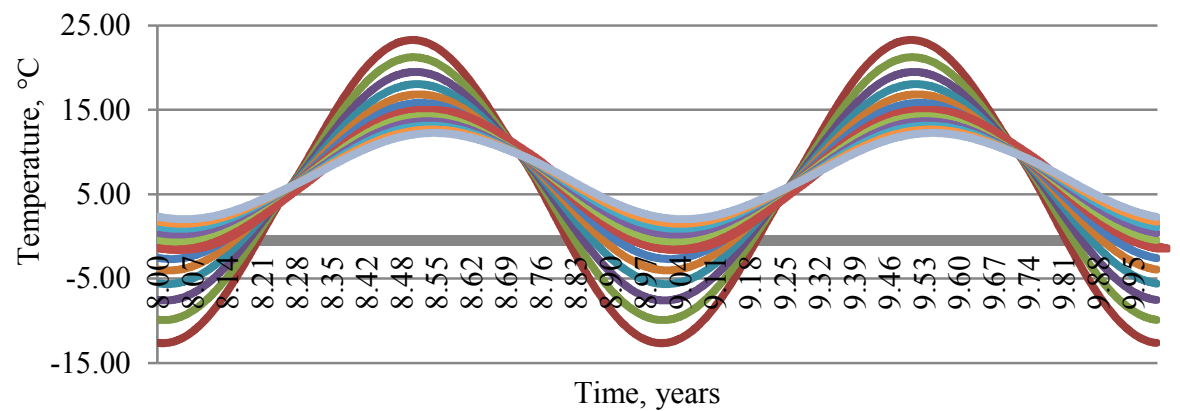

Fig. 6. Graph of influence of the outdoor air temperature alongside with the temperature in the soil column taking into account a time shift, being late in response of the temperature change.

Let us consider the temperature change in the soil column, thermal massiveness and time shift depending on the temperature of the outdoor air at a depth of $1.3 \mathrm{~m}$ to $2.4 \mathrm{~m}$ in increments of $0.1 \mathrm{~m}[11]$.

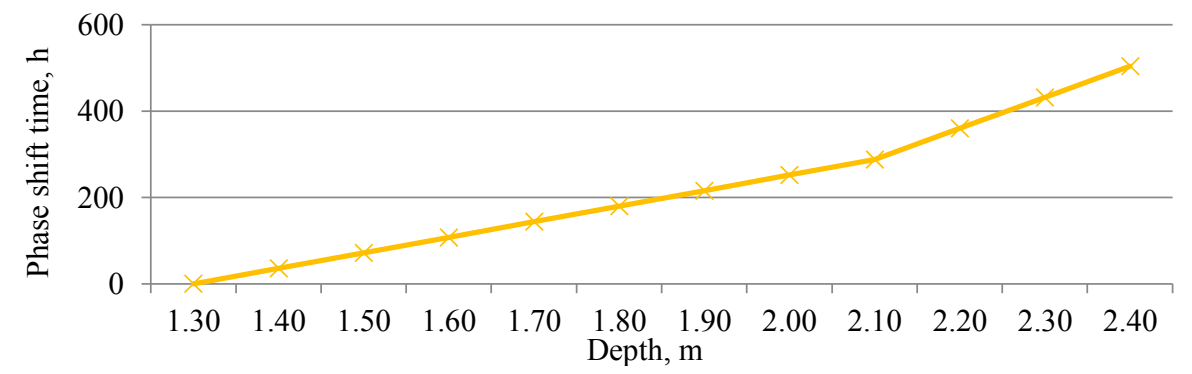

Fig. 7. Graph of the dependence of temperature variations changes in the course of time according to the laying depth of soil from $1.3 \mathrm{~m}$ to $2.4 \mathrm{~m}$ in increments of $0.1 \mathrm{~m}$.

The graph shows that with each step of deepening there is an increasing deviation in the time lag of the temperature conditions influence taking place in the soil mass minding that the temperature change does not occur immediately, but with a certain period of time equal to the time of phase shift. 


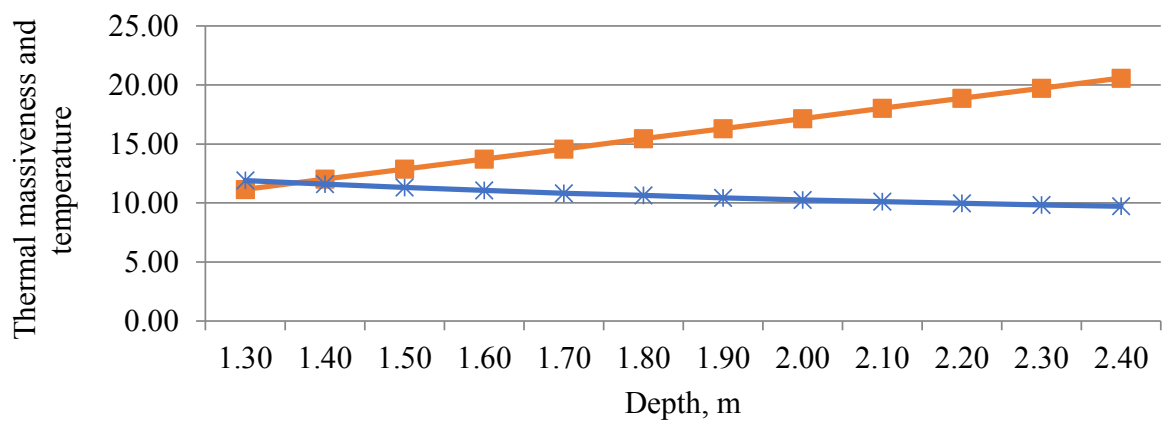

Fig. 8. Graphs of the thermal massiveness of soil and the temperature depending on the depth. (line 2 - thermal massiveness, line 5 - temperature).

The graphs show the thermal massiveness changes conditioned by further deepening while the decreasing of temperature in soil being minor. This is due to the thermal massiveness of the soil, being large enough and its increasing with each step of deepening [10].

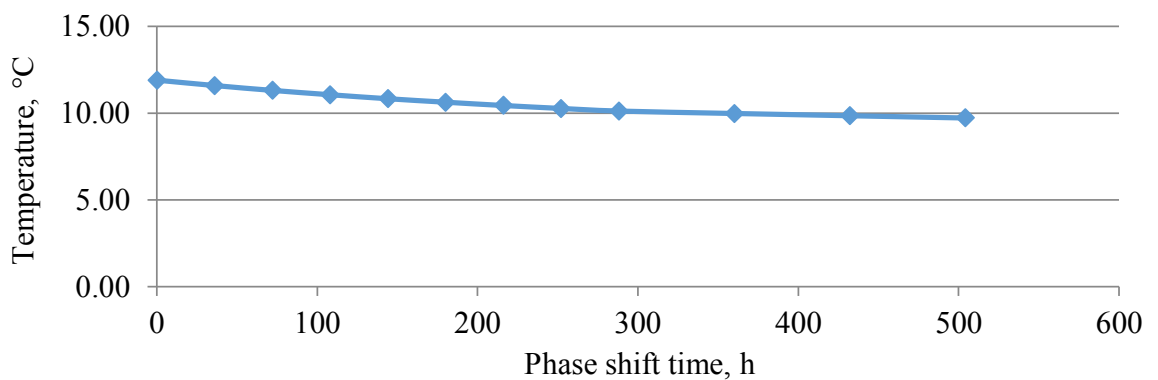

Fig. 9. Graph of temperature changes in the soil column depending on the time shift [10].

The graph in Fig. 9 shows that the longer the time lag, the lower the temperature is. However, with the time shift of about $300 \mathrm{~h}$, the temperature drop is negligible and with the further time shift, the temperature change tends to a steady-state process. Let us consider the change in temperature in the thickness of the soil, thermal massiveness and time shift, depending on the temperature of the outdoor air at a depth of $2.5 \mathrm{~m}$ to $3.5 \mathrm{~m}$ in increments of $0.1 \mathrm{~m}$ [14]. It can be seen that temperature decay and variations together with time lag of outdoor air temperature effect on soil layer decrease due to increasing of thermal massiveness of soil.

Let us consider the temperature change in the soil column thermal massiveness and time shift depending on the temperature of the outdoor air at a depth of $3.5 \mathrm{~m}$ in increments of $0.1 \mathrm{~m} \mathrm{[14]}$.

Fig. 10 present integrated graphs of the outdoor temperature effect and temperature variations decay, taking place in the soil column depending on time. 


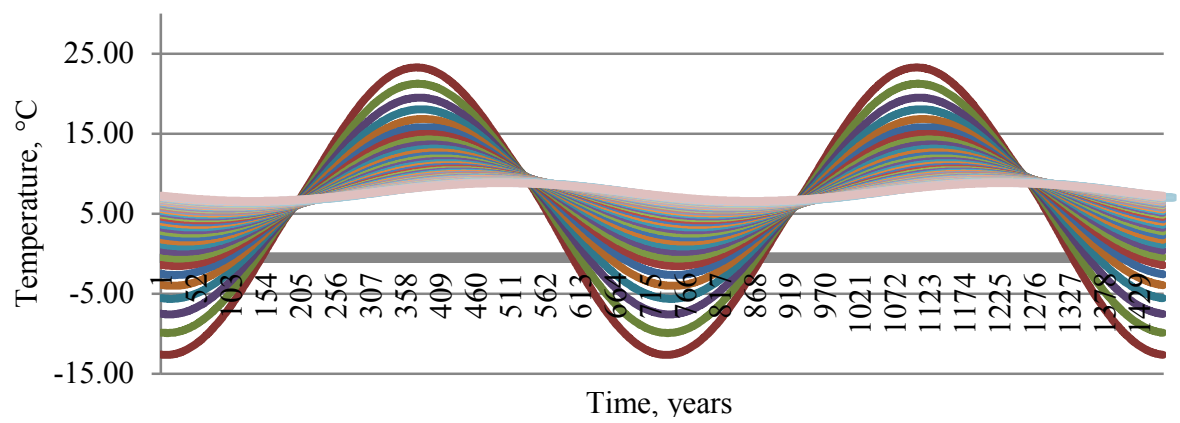

Fig. 10. Graphs of the outdoor temperature effect and temperature variations decay, taking place in the soil column depending on time.

These graphs give a complete picture of temperature variations and time delay temperature changes due to the increase in the thermal massiveness of the soil with each step of deepening. The graphs clearly show the shifts in the time of maximum temperatures and reflect a qualitative picture of the temperature variations amplitudes in the outdoor air as well as in the soil column within the period of $8-10$ years. It can be concluded that in $3.5 \mathrm{~m}$ or more soil mass deepening the outdoor air temperature effect can be neglected [11].

The type of soil examined in this paragraph was soil loam, being wet and having the following parameters: density (wet) $\rho_{\text {gr. }}=2710 \mathrm{~kg} / \mathrm{m}^{3}$; specific gravity $\gamma_{\mathrm{gr} .}=24525 \mathrm{~N} / \mathrm{m}^{3}$; coefficient of thermal conductivity (wet) $\lambda_{\text {gr. }}=1,26 \mathrm{~W} / \mathrm{m} \times{ }^{\circ} \mathrm{C}$; the heat capacity $c_{\text {gr. }}=0.84 \mathrm{~kJ} / \mathrm{kg}$. (in accordance with state standard 25100-2011. Soils. Classification.) The climatic parameters of the outdoor air were taken for the city of Moscow in accordance with set of rules 131.13330.2012 construction climatology. The updated edition of building codes 23-01-99* (with Change N 2)).

\section{Results of modelling and controlling the thermal conditions of the underground heat collector}

Fortran programming language and Force 2.0 compiler were chosen for mathematical modeling. The initial data are the following: soil temperature (initial) tgr. $0{ }^{\circ} \mathrm{C}$; the temperature of internal air tair ${ }^{\circ} \mathrm{C}$; coefficient of soil thermal conductivity $\lambda$ gr., $\mathrm{W} / \mathrm{m} \times{ }^{\circ} \mathrm{C}$; coefficient of thermal conductivity of enclosing structure layers $\lambda$ con., W/ $\mathrm{m} \times{ }^{\circ} \mathrm{C}$; coefficient of soil thermal conductivity cgr., $\mathrm{kJ} / \mathrm{kg}$; coefficient of thermal conductivity of enclosing structure layers ccon., $\mathrm{kJ} / \mathrm{kg}$; soil density $\rho g r ., \mathrm{kg} / \mathrm{m} 3$; density of enclosing structure layers $\rho$ con., $\mathrm{kg} / \mathrm{m} 3$. A segment from the supply to the exhaust shaft, shown in Fig. 11, was taken as a design element of the underground collector. The segment length is $250 \mathrm{~m}$ and the volume of the design element for modelling is $0.1 \mathrm{~m} 3$. Having separated the under-ground collector into two symmetrical parts along the length, it is divided into segments. Along the length, axis $\mathrm{k}$, the selected collector segment is divided into 2620 segments, along the width, axis i, - into 45 segments and in the depth from the ground surface, axis $\mathrm{j},-$ into 70 segments. In each of the segments the unsteady heat transfer and the effect of thermal massiveness on the delay of temperature fluctuations in time are calculated. When calculating this problem, we set the boundary conditions of the third type, set the temperature of the external and internal air, which varies over time and the processes of non-stationary heat transfer between the collector, soil and surfaces of enclosing structures and engineering communications, the air flow rate at the inlet to the supply shaft of the underground collector. The result of the calculation is the change of the collector 
thermal conditions over time and the rate change along the collector, estimation of the soil thermal massiveness affecting the temperature shift in time [12].

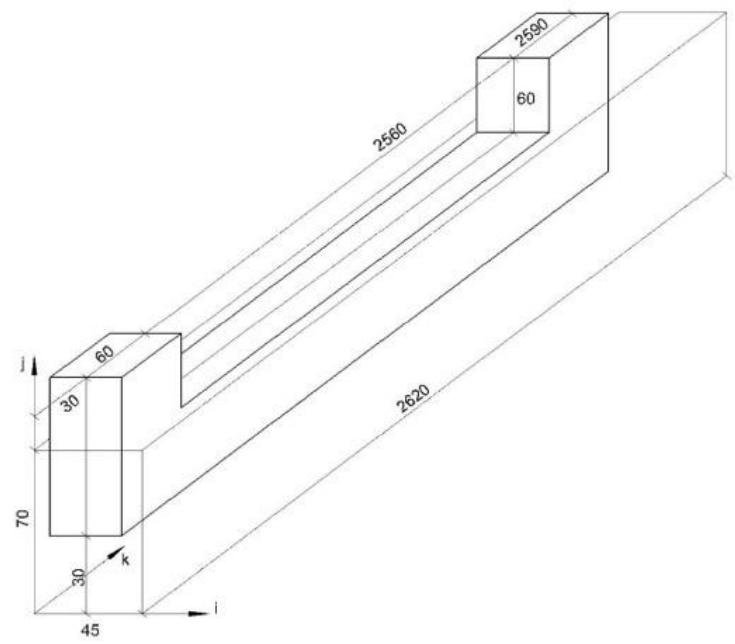

Fig. 11. Design part of the underground collector divided into segments of $0.1 \mathrm{~m}$.

Fig.13 demonstrates the graphs of changing temperature in the collector depending on time and without regard to changing outer air temperature for better consideration of temperature changes within the collector.

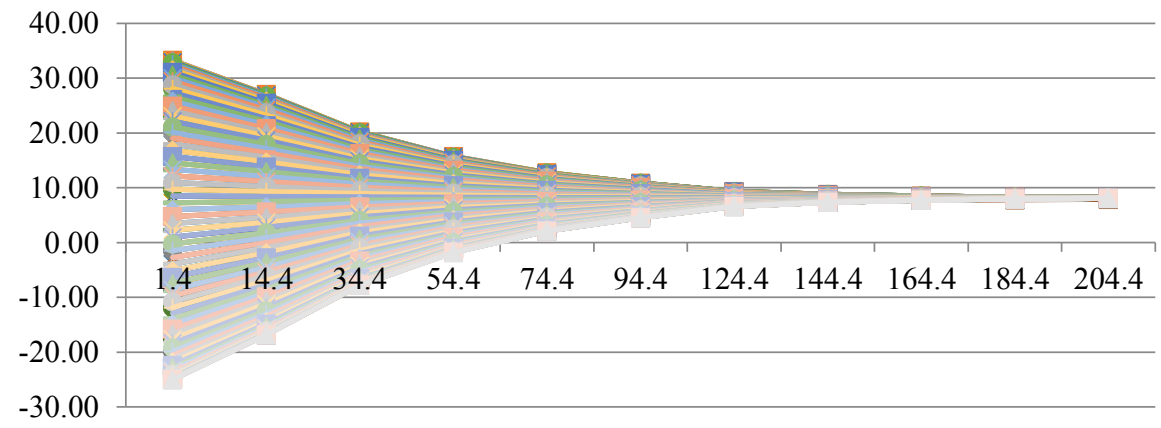

Fig. 12. Temperature field in the air along the underground collector in the range from $-25^{\circ} \mathrm{C}$ to $32^{\circ} \mathrm{C}$.

These graphs more clearly show the temperature changes within the underground collector in the range of small amplitude fluctuations, which allows seeing the shifts of the maximum temperature fluctuations over time. Graphs of Fig. 12 and 13 demonstrate how the temperature in the underground collector changes over time. The graphs show shifts of temperature maxima, they are not as pronounced as in the soil mass due to the low thermal massiveness of the air. However, it can be seen from the graphs that the temperature change is sinusoidal with some time delay and the influence of the outer inlet air has a noticeable change in thermal conditions only on a relatively small length of the collector in its initial sections. With the further passage of the air along the collector, the convective component of heat transfer and mass transfer decreases and the temperature stabilizes in the range of $+8^{\circ} \mathrm{C}\left( \pm 0.5^{\circ} \mathrm{C}\right)$, which does not go beyond the requirements of the minimum temperature of internal air in the underground collector that does not have internal heat surpluses [13]. 


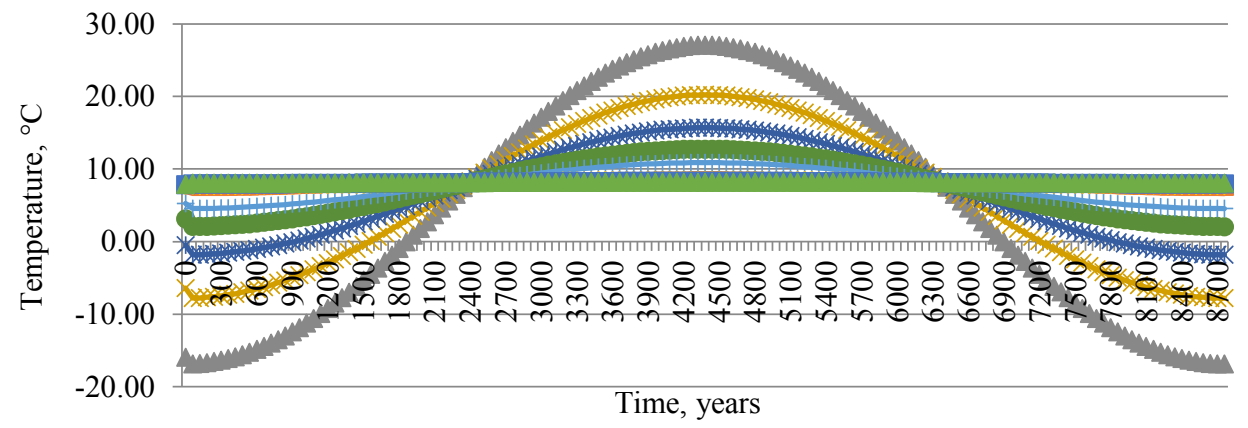

Fig. 13. Graphs of changing temperature in the collector depending on time and without regard to changing outer air temperature.

\section{Summary}

At present there are no software systems for modeling and calculating the thermal conditions of the underground collector, and it does not allow accurately calculate heat losses in the underground collector. The proposed model gives an opportunity to calculate the parameters of the underground collector thermal conditions, changing in time, which leads to lower transportation costs of thermal and electric energy and reduces energy consumption by consumers. With the help of the proposed model, it is possible to predict the processes of heat exchange in the soil mass and the effect of thermal massiveness depending on the type of soil, climatic region and effects of outer air parameters on the parameters of the collector thermal conditions in time. The problem of energy saving during transportation of heat and electricity is solved, which directly affects the reduction of energy consumption by consumers.

\section{References}

1. ASHRAE Guide And Data Book: Fundamentals and Air Conditioning Engineering, 912 (1963)

2. S. B. Carpenter, Principal Plum Dispersion Models (TVA Pow. Plants, 63 Annual Meeting, Air Pollution Assoc., June, 1970)

3. F. N. Frenkiel, R. E. Munn, Turbulent Diffusion in Enviromental Pollution (Advances in Geophysics Series, 18A and 18B, New-York, Academic Press, 1974)

4. A. N. Huber, Incorporating Building. Terrain Wake Effects on StaskEnfluent (Preprint Volume for the Joint Conf. on Applic. of Air Pollut. Metod., Amer. Meteorolog. Socity, Boston, MA, 1977)

5. O. Roberts, Proc. Roy. Soc. 104A, 11-15 (1923)

6. E. A. Skaret, H.M. Mathisen, Enviroment International 8, 473-481 (1982)

7. G. L. Tuve, Trans. ASHRAE 59, 261-282 (1953)

8. J. E. Woods, R. R. Crawford, ASHRAE Transactions, 683-696 (1983)

9. J. E. Woods, Trans. ASHRAE, 559-571 (1975)

10. O. Brukhanov, A. Rymarov, A. Malysheva, D. Titkov, Analysis of heat losses of underground tunnel for engineering utilities with available methods (Matec Web of 
Conferences 5. Cep. "5 ${ }^{\text {th }}$ Inter. Scien. Conf. "Integration, Partnership and Innovation in Construction Science and Education", 2016)

11. A. G. Rymarov, D. G. Titkov, Peculiarities of calculation of thermal regime of underground communication collector internet bulletin wolghas (Volgograd State University of Architecture and Civil Engineering, 4, 40, 6, 2015)

12. A. G. Rymarov, D. G. Titkov, Influence of the massity of the environment on the thermal regime of the underground collector for engineering communications, natural and technical sciences (OOO "Izd." Sputnik + "Moscow 6, 84, 563-564, 2015)

13. O. N. Brukhanov, A. G. Rymarov, D. G. Titkov, Analysis of methods of calculation of thermal losses by underground mounting collector, natural and technical sciences (OOO "Izd." Sputnik + "Moscow 8, 86, 89-91, 2015)

14. A. G. Rymarov, D. G. Titkov, Science of Education 10-2, 44-47 (2015) 